\title{
LEITURA E REVISÃO DE TEXTOS POR PROFESSORES EM FORMAÇÃO INICIAL
}

\author{
Natalia Gonçalves Moterani é aluna do Programa de Pós-Graduação em Letras da Universidade Estadual de Maringá. \\ E-mail: nati_moterani@hotmail.com
}

Renilson José Menegassi é Doutor em Letras e professor do Programa de Pós-Graduação em Letras da Universidade Estadual de Maringá.

\begin{abstract}
Resumo
Este trabalho, advindo dos projetos de pesquisas "Manifestações de Constituição da Escrita na Formação Docente" (SETI/FA/UEM), verifica como professores em formação, do terceiro ano do curso de Letras da Universidade Estadual de Maringá, assumem a postura de leitores para revisarem textos de alunos do Ensino Fundamental, partindo dos objetivos de compreender qual é a concepção com relação à revisão de textos manifestada e analisar o que levam em conta quando assumem a posição de co-produtores, nesse processo. Nesse sentindo, apoiamos-nos em Bakhtin (2003), Geraldi (1996), Fiad \& Mayrink-Sabinson (1994) e Sercundes (1994), no que se refere aos conceitos de interação e escrita. Os resultados revelam que os professores não possuem uma base teórico-metodológica concreta para a leitura e para a revisão, pois alguns apenas fazem a higienização do texto, enquanto outros se atentam para o conteúdo, e os apontamentos se mostram mal organizados, o que pode prejudicar o trabalho com a reescrita do aluno, por falta de conhecimento de como ser mediador desse processo.
\end{abstract}

\begin{abstract}
This work, arising out of the research projects "Manifestações de Constituição da Escrita na Formação Docente" and "Aspectos da responsividade na reescrita de textos" (SETI/FA/UEM), verifies as teachers in training, of the third year of the Language Course of Universidade Estadual de Maringá, take the attitude of readers to review texts from elementary school students, based on the objectives to understand what is the conception of the texts revision manifested and analyze what they take into account when they assume the position of co-producers. In this way, we support our study in Bakhtin (2003), Geraldi (1996), Fiad \& Mayrink-Sabinson (1994) and Sercundes (1994), with regard to the concepts of interaction and writing. The results reveal that the teachers do not have a concrete theoretical and methodological basis for reading and revision, because some just do the cleaning of the text, while others look to the content and notes are presented poorly organized, which can harm the rewrite of the student, because they do not know how to be the mediator of this process.
\end{abstract}

\section{1) Considerações iniciais}

Ao adotarmos a concepção interacionista de língua, com ênfase na abordagem sócio-histórica, verificamos que a escrita deveria ser encarada como um processo contínuo e complexo, em que, para ser eficaz, devem-se cumprir etapas como a produção textual, a revisão e a reescrita. Assim, o texto do aluno deveria ser compreendido como provisório, sujeito a várias versões, de preferência mediadas pelo professor. Contudo, a prática em sala de aula nos revela que o trabalho com a escrita restringe-se, muitas vezes, à higienização do texto do aluno, isto é, à verificação de sua superficialidade linguística, o que apenas aponta as inadequações com relação à estrutura gramatical da língua. Dessa forma, este trabalho verifica como professores em 
formação, do terceiro ano do curso de Letras da Universidade Estadual de Maringá, assumem a postura de leitores para revisarem textos, partindo dos objetivos de a) compreender qual é a concepção de escrita manifestada por eles; b) analisar o que levam em conta quando assumem a posição de co-produtores no processo.

Nesse sentido, como amostra representativa das análises realizadas, observaremos três práticas de revisão, com apontamentos para reformulação, em textos de alunos da $7^{\text {a }}$ série do Ensino Fundamental de uma escola regular, a fim de verificar como os graduandos, enquanto professores em formação e leitores, revisam esses textos e se posicionam como mediadores. Para tanto, apoiamos-nos em Bakhtin (2003), o qual afirma que toda comunicação apresenta uma alternância de vozes advindas de outros enunciados; na concepção de escrita como trabalho, proposta por Geraldi (1996), Fiad \& Mayrink-Sabinson (1994) e Sercundes (1997), a qual revela que a escrita é um processo contínuo de interação, em que se cumprem etapas como a revisão e a reescrita; e em Ruiz (2010), a qual classifica uma série de estratégias para a revisão de textos.

\section{2) Interação e escrita}

Longe de uma conduta que preconiza a língua como sistema único, apoiamo-nos na teoria bakhtiniana, a qual parte da concepção de linguagem interacionista, elencando algumas características apontadas por seu Círculo de estudos em relação ao discurso, especificamente, para esta pesquisa, à escrita. Dessa forma, ao relacionarmos interação e comunicação, temos que considerar o papel do ouvinte, o qual Bakhtin convencionou chamar de outro, que é, na verdade, o interlocutor desse processo de comunicação.

Fora de um conceito tradicional que estabelece a comunicação entre locutor e ouvinte passivo, o outro é peça fundamental para que se estabeleça um diálogo, pois suas atitudes responsivas permitem que se estabeleça e se continue a interação. Contudo, para que isso ocorra, ele deve ser concebido como sujeito ativo participante, pois, inserido em um elo comunicativo e ao compreender o sentido do discurso proferido por outrem, ocupa uma atitude responsiva diante de tal situação, a qual se efetiva tanto na fala, quanto na escrita.

Nesse movimento comunicativo, o ouvinte se torna falante, já que, no cerne do discurso vivo, "toda compreensão é prenhe de resposta" (BAKHTIN, 2003, p. 271). Assim, estabelecidos os laços da interação verbal entre dois indivíduos, temos o produto desse processo: a enunciação dialógica, pois o sujeito não só espera a resposta do outro, como também, constrói o seu processo interno da palavra por meio da palavra do outro, visto que "o mundo interior e a reflexão de cada indivíduo têm auditório social próprio bem estabelecido, em cuja atmosfera se constroem suas deduções interiores, suas motivações, apreciações, etc." (BAKHTIN/VOLOCHINOV, 1992, p. 112).

Nos domínios da escrita, podemos afirmar que, primeiramente, a alternância de sujeitos se dá entre as vozes de outros enunciados, visto que "as palavras podem entrar no nosso discurso a partir de enunciações individuais alheias, mantendo em menor ou 
maior grau os tons e ecos dessas enunciações individuais" (BAKHTIN, 2003, p. 293). Posteriormente, o diálogo de um discurso escrito ocorrerá entre o locutor e o interlocutor, os quais, por meio de uma relação de responsividade, trocarão informações, idéias, conceitos para juntos construírem um sentido para o texto.

O contato com o alheio é fundamental para a comunicação e, consequentemente, para a construção cultural de um sujeito socialmente organizado, pois é a partir do contexto sócio-histórico que sua aquisição ideológica acontecerá e refletirá tanto na fala como na escrita. Com relação a isso, podemos nos apoiar nos estudos de Bakhtin/Volochinov (1992) e em Vygotsky (1998), os quais acreditam que a construção do conhecimento humano parte do social para o individual, em um processo que Bakhtin chama de monologização da consciência e Vygotsky denomina de internalização. Ambos se apóiam na teoria de que a consciência sofre um rearranjo e uma reformulação a partir de informações que recebe do exterior, ou seja, do social, por meio do contato que um sujeito estabelece com outros indivíduos. Esse contato pode ser efetuado diretamente pela fala, ou por meio de um texto escrito, já que, nos dois casos, a interação acontece. Assim, Bakhtin/Volochinov afirmam que

a atividade mental do sujeito constitui, da mesma forma que a expressão exterior, um território social. Em conseqüência, todo o itinerário que leva da atividade mental (o "conteúdo a exprimir") à sua objetivação externa (a "enunciação") situa-se completamente em território social. Quando a atividade mental se realiza sob a forma de uma enunciação, a orientação social à qual ela se submete adquire maior complexidade graças à exigência de adaptação ao contexto social imediato no ato de fala, e, acima de tudo, aos interlocutores concretos. (BAKHTIN/VOLOCHINOV, 1992, p.117)

Sob essa mesma vertente, ao estudar o processo de aprendizagem das crianças, os estudos de Vygotsky vêm somar aos de Bakhtin, postulando que a internalização é a reconstrução interna de uma operação externa.

um processo interpessoal é transformado num processo intrapessoal. Todas as funções no desenvolvimento da criança aparecem duas vezes: primeiro no nível social, e, depois, no nível individual; primeiro, entre pessoas (interpsicológica), e, depois, no interior da criança (intrapsicológica). (...) Todas as funções superiores originam-se das relações reais entre indivíduos humanos. (VYGOTSKY, 2003, p. 75)

Essa perspectiva nos mostra novamente que o fator social e a consideração do outro estão indissoluvelmente ligados à língua, ou, para sermos mais exatos, à sua aquisição no que concerne fala e escrita. Dessa forma, acredita-se que o ensino da escrita esteja voltado ao uso dos gêneros discursivos, pois são eles que circulam na vida dos alunos, são construtos envoltos em situações sociais concretas e únicas e, ainda, são enunciados que efetuam o emprego da língua em essência (BAKHTIN, 2003). Acerca disso, se o ensino estivesse alinhado a essa nova tendência, a escrita estaria exposta a todas as características da interação verbal que descrevemos, visto que ela se voltaria a um fim social. Além disso, os alunos passariam de meros receptáculos de informação a 
sujeitos participantes, os quais são aptos a interagirem com o professor e com o próprio texto, já que esse último é a principal ferramenta para a interação verbal e, dessa forma, deve ser o ponto de partida para o ensino de línguas. Assim, o papel do professor perante essa situação é o de mediador entre o texto e o aluno, sendo o par superior que opera sob as informações que ambos revelam, contribuindo para que o aprendiz desenvolva práticas discursivas, com as quais os indivíduos agem socialmente. Portanto, amparados em Bakhtin, tudo o que descrevemos mostra que o ensino de línguas, mais precisamente da escrita, deve abordar o contexto sócio-histórico do aluno e não deixar de lado a presença de um interlocutor, ou seja, o outro como peça fundamental para a concretização do discurso, levando em consideração a troca de informações, de cultura para a construção de um sentido para o texto em Língua Materna.

\section{3) As concepções de escrita}

Dentre os estudos desenvolvidos sobre a escrita, sobretudo os de Geraldi (1996), Fiad \& Mayrink-Sabinson (2001) e Sercundes (1997), encontramos algumas concepções delineadas por esses teóricos sobre o discurso escrito. Nesse contexto, destacamos algumas delas, as quais nortearão nossas análises.

Fiad \& Mayrink-Sabinson (2001) e Sercundes (1997) apontam que a primeira concepção vê a escrita como um dom, uma inspiração, a qual advém das emoções de quem está produzindo o texto. Dessa forma, a escrita não parte de atividades prévias e tampouco exige o trabalho com a reescrita, já que isso inibiria a inspiração natural de quem escreve, pois ela é vista como "fruto de uma emoção, de um momento de inspiração" (FIAD \& MAYRINK-SABINSON, 2001, p. 57).

Uma segunda concepção revela que a escrita é uma consequência de atividades prévias como a leitura de um texto, comentários em sala de aula, debates e, até mesmo, de um filme. Essa concepção segue o exemplo da maioria dos livros didáticos os quais apresentam tais atividades como pretexto para a escrita, o que, de acordo com Sercundes, as tornam "previstas, controláveis, porque o material não é formulado para o professor usá-lo, e sim para segui-lo.” (1997, p. 80).

No que diz respeito à terceira concepção, ela encara a escrita como trabalho e contempla também as atividades prévias, as quais são evidenciadas pela escrita como consequência, no entanto, elas são vistas como suporte para o exercício da produção textual. Nesse sentido, a expressão "trabalho" demonstra que essa concepção concebe o ato de escrever como um esforço do indivíduo, já que, de acordo com Fiad \& MayrinkSabinson (2001), a escrita é vista como um processo contínuo e complexo que abarca planejamento, execução, revisão e modificação, por meio da reescrita, o que evidencia "um trabalho consciente, deliberado, planejado, repensado" (FIAD \& MAYRINKSABINSON, 2001, p. 63).

Com relação a isso, afirmamos que esta última concepção é a que permite o mecanismo do dialogismo, já que aborda a questão da interação entre sujeitos, o que nos 
remete à responsividade, proposta por Bakhtin (2003). Sendo assim, é por meio dela que todo o procedimento envolvendo a produção textual deve acontecer, isto é, o trabalho com a escrita deve proporcionar o desenvolvimento efetivo da habilidade de produzir textos.

\section{4) Leitura e estratégias de revisão de textos}

Ao adotarmos a concepção de escrita como trabalho, não podemos isentar o importante papel do leitor, isto é, do professor, o qual, juntamente com os alunos, vai construir em um processo de co-produção, o sentido para os textos. Sob este viés, o caráter responsivo da linguagem, delineado por Bakhtin (2003), se concretiza, visto que ao ler e revisar o texto do aluno, o professor imediatamente contribui para que algumas lacunas deixadas pelos produtores sejam preenchidas, por meio das inferências que faz, enquanto leitor, e de seus apontamentos, no papel de revisor. Entretanto, nem sempre esses espaços são completados, já que ler e revisar geralmente consistem na procura dos erros que o texto apresenta, ou seja, é muito mais comum que o professor faça apenas a higienização da superfície, corrigindo as inadequações gramaticais que o aluno demonstra, ao produzir seu texto.

A respeito disso, Ruiz (2010), ao se basear no trabalho de Serafini (1989), classifica algumas estratégias para a revisão de textos por parte do professor, as quais dependem da leitura que este tem o hábito de fazer, assumindo o papel de interventor, ou de co-produtor das produções textuais:

- a correção indicativa, a qual tem por objetivo marcar as inadequações do textos, por meio de sinalizações que os professores fazem, apontando apenas o local, o qual deve ser alterado pelo aluno. Essa estratégia é percebida quando o professor sublinha, risca, circula ou faz um $\mathrm{X}$ em algum termo, expressão ou pontuação do texto;

- a correção resolutiva, que consiste em corrigir todos os erros das produções textuais, reescrevendo palavras, frases e até períodos inteiros. Com esta estratégia, o professor assume a função do aluno de reescrever seu texto, pois ele próprio já o faz;

- a correção classificatória, a qual revela um conjunto de símbolos utilizado pelos professores para apontarem os erros dos alunos. Em geral, eles utilizam as letras iniciais de um termo metalinguístico referente à natureza do problema em questão, por exemplo, "Coer" para indicar que dado texto apresenta problemas como a coerência, ou "M", apontando que certa palavra deve começar com letra maiúscula; 
- a correção textual-interativa, a qual revela comentários mais longos que são dispostos logo em seguida do textos do aluno. Esses apontamentos normalmente se realizam em forma de pequenos bilhetes, os quais têm por objetivo falar sobre as inadequações das produções textuais, de modo que, neste caso, o professor não apenas aponta os erros do modo de dizer do aluno, como acontece nos demais tipos de correção, mas se atenta para o dizer deste, ou para sua atitude comportamental refletida em seu dizer. Assim, professor e aluno conversam por meio dos bilhetes no próprio texto do aluno, dialogam em um movimento interativo, o qual evidencia a atitude responsiva que as tarefas de produção e co-produção textual requerem.

Destacamos que nos três primeiros modos de correção, o professor é apenas o avaliador do texto, já que seus apontamentos servem apenas para mostrar os erros da escrita dos alunos. No que se refere ao último tipo de correção, podemos dizer que esta apresenta um professor que assume o papel de co-produtor, já que os bilhetes, que na verdade são os apontamentos do docente ao aluno, além de mostrarem as inadequações do texto, também apontam o que está de acordo, por meio dos comentários que esta estratégia permite que se faça. Ela ainda proporciona um diálogo entre produtores e coprodutores, o que evidencia o caráter interativo deste tipo de revisão.

\section{5) Leitura e revisão de textos por professores em formação}

Passaremos às análises a respeito de como professores em formação, do terceiro ano do curso de Letras da Universidade Estadual de Maringá, assumem a postura de leitores para revisarem textos produzidos por alunos da $7^{a}$ série do Ensino Fundamental de uma escola regular. Para tanto, observaremos três práticas distintas de revisão de um mesmo texto, com apontamentos para a posterior reformulação. Esses professores foram solicitados a apresentar apontamentos ao texto, para que o aluno efetivasse a revisão no material escrito, levando à reescrita do seu texto. Essa prática ocorreu durante os estudos teórico-metodológicos sobre o processo de produção textual em situação de ensino, na disciplina Linguística Aplicada e Ensino-Aprendizagem de Língua Materna, no ano de 2010. 
Texto 01

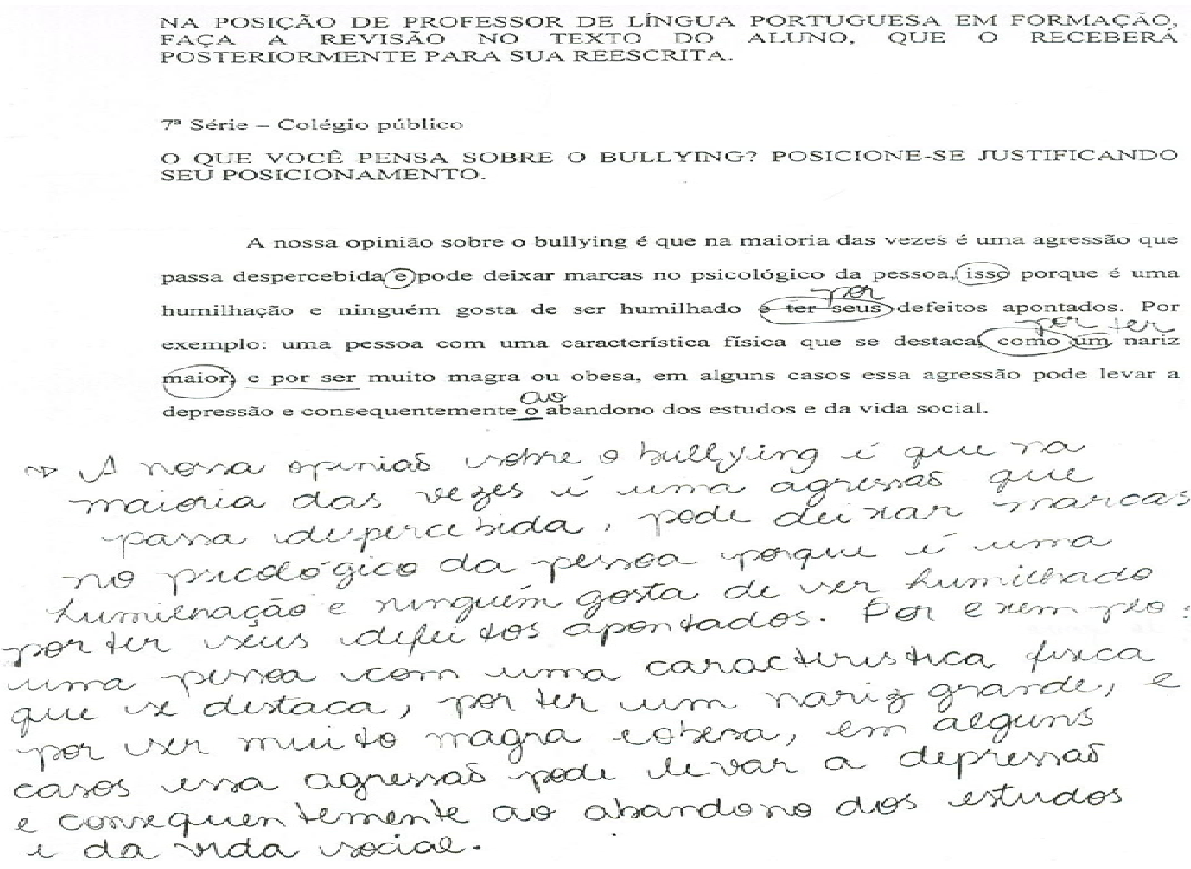

Nesta primeira ocorrência, verificamos que, o professor em formação marca as possíveis inadequações a respeito da estrutura das frases que constroem o texto, o que nos permite visualizar que ela utiliza a correção indicativa, uma vez que aponta os erros com sublinhados e círculos. Nesse sentido, esse professor higieniza o texto do aluno, sem se atentar para questões como sua estrutura e temática, já que se trata do gênero discursivo resposta, com características argumentativas. Essa atitude possivelmente faria com que o aluno apenas passasse o texto a limpo, copiando o que o revisor apontou de inadequado. Entretanto, além de fazer a correção indicativa no próprio corpo textual, o professor apresenta a correção resolutiva, uma vez que passa a limpo o texto do aluno no espaço posterior a ele, inibindo, dessa forma, uma possível reformulação, a qual faz parte do momento da reescrita textual, uma das etapas para que o processo de escrita se cumpra, de modo que ela seja vista como trabalho.

Assim, é evidente que este tipo de revisão não colabora para a reflexão a cerca do que o aluno precisa melhorar em seu texto, visto que não há a negociação com seu revisor, pois este preferiu dar a resolução de todos os problemas da resposta do aluno de maneira pronta e inquestionável, interrompendo qualquer manifestação de diálogo possível. Essa prática torna a escrita um mero pretexto, uma vez que pode ser encarada como uma consequência para atividades em sala de aula, não proporcionando a reflexão por parte do aluno, inibindo o seu desenvolvimento como produtor textual. Com relação a isto, o professor passa a ser visto como um avaliador, o qual não está sujeito a trocas de informações, já que não se atenta para o conteúdo, mas avalia apenas os erros gramaticais que o texto apresenta. Desse modo, o papel de co-produtor simplesmente não existe e a escrita fica estanque, pois é interrompida em uma primeira versão. 
Texto 02



No que se refere à segunda revisão textual, percebemos que o professor também marca as inadequações do texto com alguns sublinhados, demonstrando que utiliza a correção indicativa. Contudo, não vai além disso, já que aponta o erro e já o corrige logo acima da palavra ou expressão destacada, manifestando o que compreender como indicação de revisão.

A primeira manifestação da correção indicativa está relacionada ao comando de produção, pedindo que seja dada a posição do aluno com relação ao tema proposto para a resposta. Ao perceber que o aluno inicia seu texto com a expressão "A nossa opinião sobre o bullying", o revisor imediatamente faz esta marca, circulando o pronome "você" do comando e sublinhando a palavra "nossa" da produção textual. Este seria um tipo de correção inválido, visto que um aluno desavisado a respeito do apontamento não saberia do que se trata, mas, além de fazer essa indicação, o docente escreve, acima da palavra que julgou inadequada, o pronome que condiz com o que pede o comando de produção. Entretanto, o que nos chama a atenção é o fato de que esse tipo de apontamento, apesar de ser eficaz no momento da reescrita, não proporciona a reflexão do aluno a respeito do que precisa ser melhorado em seu texto, já que a resposta já vem pronta, impedindo o aprendizado e o desenvolvimento referentes ao discurso escrito.

Outro aspecto dessa revisão é o de que o revisor, ao dar continuidade à correção indicativa, ignora algumas palavras utilizadas pelo aluno e as substitui por outras, as quais, certamente, julga mais adequadas, como, por exemplo, quando sublinha a palavra "consequentemente" e sugere a expressão "ter como consequência". Esse tipo de apontamento não nos parece muito necessário, já que não altera o sentido do período, o que pode fazer com que o aluno opte por acatar ou não essa correção. Outro exemplo parecido com este é o acréscimo de expressões ao texto do aluno, o que também não é necessário, já que não apresenta alteração para o sentido do texto, como no caso em que 
o revisor acrescenta "um distanciamento" ao período "essa agressão pode levar a depressão e consequentemente o abandono dos estudos e da vida social".

Destacamos que a intenção do revisor era a de melhoria para o texto, mas suas indicações para que isso ocorresse não revelam alterações no conteúdo do texto referente à sua temática, visto que os apontamentos e os acréscimos que faz são irrelevantes para que isso aconteça. Nesse contexto, diferentemente do primeiro caso de revisão, esta dá espaço para que a reescrita ocorra, mas ela não apresentaria avanços no que se refere à temática do texto e a própria escrita do aluno. $\mathrm{O}$ caráter interativo da produção e co-produção é nulo, uma vez que a responsividade por parte do aluno não existe, devido ao fato de as correções estarem indicadas no texto, o que sugere apenas a cópia e não a reflexão para a melhora da escrita de uma possível segunda versão. Essa estratégia impede a manifestação da responsividade, consequentemente, do dialogismo.

Texto 03

77 Série - Colégio público

O QUE VOCE PENSA SOBRE O BULLYING? POSICIONE-SE JUSTIFICANDO SEU POSICIONAMENTO.

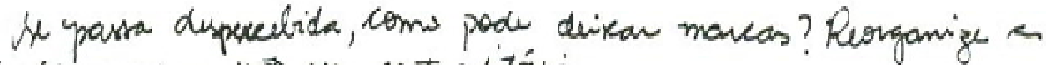
C vidum para nos se contraditove.

A nossá opinião sobre o bullying é que

passa despercebida e pode deixar marcas no psicológico da pessoo, isso porque ś uma se devace humilhạ̧a e tinguém gosta de ser hurnilhado o ter seus defeitos apontados. Por em que sentids? exemplo: uma pessoa com una característica fisica que se destach, como um nariz $E^{2}$, alga hom

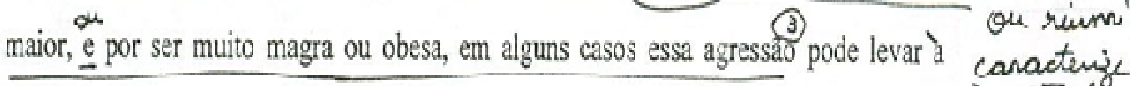

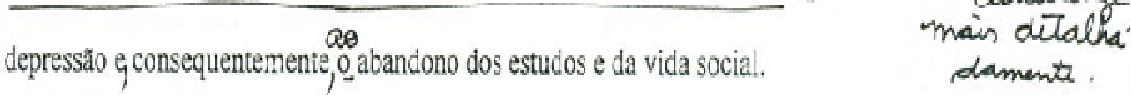


w bullying, responde em I' pesser do singulaw;

(2) Que Tupo de pessoas! Evomeas? foum? Apewiqur;

(3) Salhas ne couss verigarize speviods;



examplos mais clawes exponta mithos su ponto de vita, tois

a vespota pion supericial. 
Passaremos para a análise da última revisão, a qual se diferencia das duas outras apresentadas. Nesta ocorrência, percebemos apontamentos diferenciados, com a configuração de pequenos comentários a respeito do texto revisado. Assim, neste caso, o professor em formação se vale de uma técnica diferenciada das duas expostas anteriormente, pois se atenta mais para o conteúdo do que para a forma, o que acabou por revelar uma postura de co-produtor de sua parte.

Com relação a isso, o docente também utiliza a correção indicativa, como podemos perceber nos círculos e sublinhados que a revisão apresenta. Contudo, desta vez, ela é utilizada para apontar questões relacionadas ao conteúdo que, por sua vez, indica melhoria no que se refere à coerência e informatividade do texto. A exemplo disso, podemos observar o círculo feito no verbo destacar, o qual aponta para um comentário a respeito do que poderia complementá-lo para fazer sentido e deixar a informação completa.

Nesse sentido, a revisão é feita à base dos comentários que seguem no espaço posterior ao texto. Dessa forma, ele sublinha e circula as inadequações no corpo textual e comenta, na maioria das vezes, no espaço seguinte ao texto e isso é aplicável, já que ele organiza seus comentários por meio dos números que acompanham o destaque dos períodos sublinhados, o que facilita a compreensão e leitura do aluno no que se refere a isso. Assim, em 1, temos, um comentário semelhante ao apontamento da revisão anterior, a respeito do uso do pronome "minha", em detrimento do "nossa". Entretanto, o revisor não dá a resposta pronta, como observamos na ocorrência anterior, mas faz que o aluno reflita sobre o uso dos pronomes da primeira pessoa do singular e do plural e da escolha mais adequada para a resposta.

Em 2, percebemos a preocupação do revisor no que se refere ao recorte temático, estimulando o aluno a apontar o tipo de bullying que está abordando, isto é, se está tratando do que afeta as crianças, jovens ou, até mesmo, adultos, pois, ao acatar o comentário, ele necessariamente precisa rever outros pontos em seu texto, referentes a essa questão. Já em 3, em vez de indicar uma maneira mais adequada para se reescrever o período, o professor em formação apenas o mostra, revelando falhas na coesão e solicitando a sua reorganização, comentário que necessitaria de um pouco mais de elaboração, já que ao ler o próprio texto, dificilmente, o aluno encontra suas próprias falhas.

Desse modo, em geral, essa revisão é a que mais se aproxima do modelo de correção textual-interativa, uma vez que a preocupação do revisor é a de melhorar questões como a coerência e a informatividade do texto, como verificamos no último comentário que tece a respeito da exposição do posicionamento do aluno, para que a resposta elaborada por ele saia da superficialidade de informações. Portanto, destacamos que esse tipo de revisão é a que se encaixa na concepção de escrita como trabalho, pois ao fazer parte das etapas do processo que ela propõe, permite que se avance e, consequentemente, se cumpra a etapa posterior a esta, que é a reescrita. No que diz respeito a isso, esse tipo de revisão também garante a responsividade imediata por parte 
do revisor, que assume a postura de leitor e co-produtor textual, bem como a resposta posterior a esse trabalho, advinda das outras versões do texto que essa primeira revisão poderá proporcionar. Assim, ao dar espaço para que a responsividade ocorra, estabelece-se a interação, base concreta que estimula, em um processo de negociação de informações, o desenvolvimento do discurso escrito.

\section{6) Considerações finais}

As três práticas de revisão observadas e analisadas revelam a postura dos professores em formação, enquanto leitores, no que concerne à mediação e revisão de textos da $7^{\mathrm{a}}$ série do Ensino Fundamental. Assim, no âmbito analítico, os resultados revelam que nem sempre esses alunos encaram a escrita como um processo que requer trabalho e, muitas vezes, se portam como avaliadores das produções textuais, dispensando o ato de co-produzir sentidos. Nesse contexto, destacamos que:

a) os professores em formação não possuem uma base teórico-metodológica concreta para a leitura e para a revisão, uma vez que, apesar de termos analisado apenas três ocorrências, já notamos que as técnicas para esta prática divergem;

b) a técnica de correção mais utilizada é a indicativa, pois higienizar um texto é a prática mais comum quando se revisa um texto;

c) alguns graduandos apenas fazem a higienização da escrita, enquanto outros se atentam para o conteúdo, esboçando comentários que se preocupam com o nível de informatividade e coerência do texto;

d) os apontamentos se mostraram desorganizados, o que pode prejudicar o trabalho com a reescrita do aluno, isto é, quando se mostram mal formulados, os apontamentos e comentários podem não ser compreendidos pelos alunos, já que estes muitas vezes não os entendem e acabam por ignorá-los;

e) ao se comportar como avaliador, como no primeiro caso analisado, o professor inibe a reescrita, visto que a revisão do texto não permite a negociação de sentidos com o alunos e o que for determinado na correção fica estabelecido como verdade absoluta, inibindo as possíveis versões que poderiam surgir;

f) no papel de co-produtores, os professores em formação revelam que é possível que se estabeleça a interação entre o produtor textual e o revisor, pois a responsividade é ativada, tanto de quem lê e revisa, como de quem produz e reproduz o texto, já que a negociação de sentidos é efetivada na troca de informações que se estabelece por meio do processo de ler, revisar e reescrever.

Revista Escrita

Rua Marquês de São Vicente, 225 Gávea/RJ CEP 22453-900 Brasil 
Portanto, esperamos que este trabalho possa contribuir para que o estudo referente ao processo da escrita seja levado em conta desde a graduação, pois, por serem professores em formação, é provável que demonstrem incongruências com relação ao ensino de línguas, mais especificamente, no que diz respeito à escrita. Contudo, este não é um problema que se restringe aos alunos da graduação, já que observamos uma série de equívocos por parte dos professores que estão há tempo no mercado de trabalho. Dessa forma, ponderamos que a noção de corrigir e revisar as produções textuais deve ser adquirida ainda na graduação, que é o espaço dedicado à aprendizagem da relação teórico-metodológica para, posteriormente, colocá-la em prática.

\section{Referências Bibliográficas}

BAKHTIN, M. A estética da ciração verbal. 4. ed. São Paulo: Martins Fontes, 2003.

BAKHTIN, M. / VOLOCHINOV, M. Marxismo e filosofia da linguagem. 6. ed. São Paulo: Hucitec, 1992.

FIAD, R. S.; MAYRINK-SABINSON, M. L. T. "A escrita como trabalho". In: MARTINS, M. H. Questões de linguagem. São Paulo: Contexto, 2001, p. 54-63.

GERALDI, J. W. Linguagem e ensino: exercícios de militância e divulgação. Campinas: Mercado de Letras, 1996.

RUIZ, E. D. Como corrigir redações na escola. São Paulo: Contexto, 2010.

SERCUNDES, M. M. I. "Ensinando a escrever". In: GERALDI, J.W.; CITELLI, B. (Org.). Aprender e ensinar com textos dos alunos. vol 1. São Paulo: Cortez, 1997, p. 75-97.

VYGOTSKY, L. S. A formação social da mente. 2. ed. São Paulo: Martins Fontes, 2003. 